\title{
High Temperature Annealing Studies on the Piezoelectric Properties of Thin Aluminum Nitride Films
}

\author{
R. Farrel1 ${ }^{a, b}$, V. R. Pagan ${ }^{b}$, A. Kabulski ${ }^{b}$, Sridhar Kuchibhatla ${ }^{b}$, J. Harman ${ }^{a, b}$, \\ K. R. Kasarla ${ }^{b}$, L. E. Rodak ${ }^{b}$, P. Famouri ${ }^{a, b}$, J. Peter Hensel ${ }^{a}$, and D. Korakakis ${ }^{a, b}$ \\ ${ }^{a}$ National Energy Technology Laboratory, P.O. Box 880, Morgantown, WV 26507-0880 \\ ${ }^{b}$ Lane Department of Computer Science and Electrical Engineering, West Virginia University, \\ Morgantown, West Virginia 26506
}

\begin{abstract}
A Rapid Thermal Annealing (RTA) system was used to anneal sputtered and MOVPEgrown Aluminum Nitride (AlN) thin films at temperatures up to $1000^{\circ} \mathrm{C}$ in ambient and controlled environments. According to Energy Dispersive X-Ray Analysis (EDAX), the films annealed in an ambient environment rapidly oxidize after five minutes at $1000^{\circ} \mathrm{C}$. Below $1000^{\circ} \mathrm{C}$ the films oxidized linearly as a function of annealing temperature which is consistent with what has been reported in literature [1]. Laser Doppler Vibrometry (LDV) was used to measure the piezoelectric coefficient, $d_{33}$, of these films. Films annealed in an ambient environment had a weak piezoelectric response indicating that oxidation on the surface of the film reduces the value of $d_{33}$. A high temperature furnace has been built that is capable of taking in-situ measurements of the piezoelectric response of AlN films. In-situ $d_{33}$ measurements are recorded up to $300^{\circ} \mathrm{C}$ for both sputtered and MOVPE-grown AlN thin films. The measured piezoelectric response appears to increase with temperature up to $300^{\circ} \mathrm{C}$ possibly due to stress in the film.
\end{abstract}

\section{INTRODUCTION}

Aluminum nitride is an attractive material for the fabrication of MicroElectroMechanical Systems (MEMS) due in part to its piezoelectricity, inertness and tolerance to high temperatures. AlN remains piezoelectric after annealing at temperatures as high as $1000^{\circ} \mathrm{C}$, while other materials with a higher piezoelectric response (e.g. PZT) lose their properties after annealing above their Curie temperature well below $1000^{\circ} \mathrm{C}$. Annealing AlN at high temperatures in an ambient environment causes the surface of the film to oxidize. AlN begins to oxidize in an ambient environment at $800^{\circ} \mathrm{C}$ and the oxidation abruptly increases at an annealing temperature of $1000^{\circ} \mathrm{C}[1]$. This surface oxidation drastically reduces the displacement of piezoelectric films.

In-situ measurements of AlN films using Laser Doppler Vibrometry are not widely reported. Kano et al used rf-sputtered $1200 \mathrm{~nm}$ thick AlN films to reveal that AlN can be used as an actuator with a constant output velocity up to $300^{\circ} \mathrm{C}$ [2]. They reported a constant $\mathrm{d}_{33}$ value of $1.38 \mathrm{pC} / \mathrm{N}$ at temperatures ranging from $20^{\circ} \mathrm{C}$ to $300^{\circ} \mathrm{C}$. The results of high temperature measurements of sputtered and MOVPE-grown AlN films as actuators will be discussed in this paper. 


\section{EXPERIMENT}

This study reports the effects of high temperature annealing on sputtered and MOVPEgrown AlN thin films. Sputtered films were deposited onto a $350 \mu \mathrm{m}$ thick $\left(\begin{array}{lll}1 & 0 & 0\end{array}\right)$-oriented $p$ type silicon substrate using a DC magnetron sputtering technique in an $\mathrm{Ar} / \mathrm{N}_{2}$ environment at room temperature. The sputtering parameters are outlined in Table 1. MOVPE-grown AlN was also grown in an AIXTRON 200/4 RF-S horizontal reactor on 2 inch (1 00 l $)$ p-type silicon substrates. The growth temperature was approximately $1100^{\circ} \mathrm{C}$ and the reactor pressure was 50 mbar. Trimethylaluminum (TMAl) and ammonia $\left(\mathrm{NH}_{3}\right)$ were used as $\mathrm{Al}$ and $\mathrm{N}$ source precursors with flows of $12 \mu \mathrm{mol} / \mathrm{min}$ and $1.5 \mathrm{slm}$ respectively. Hydrogen was used as the carrier gas.

Table 1

Sputtering conditions of the AlN films

\begin{tabular}{|l|l|}
\hline Parameter & Value \\
\hline Al Target (\%) & 99.999 \\
\hline DC Power (W) & 500 \\
\hline Substrate Temperature & Room Temperature \\
\hline Sputtering Pressure (mTorr) & 30 \\
\hline Sputtering time (minutes) & 35 \\
\hline $\mathrm{N}_{2}$ concentration (\%) & 99.999 \\
\hline $\mathrm{Ar} / \mathrm{N}_{2}$ & $3 / 27$ \\
\hline
\end{tabular}

The AlN thin films were annealed in an Annealsys AS-Micro Rapid Thermal Annealing (RTA) furnace at temperatures ranging from room temperature to $1000^{\circ} \mathrm{C}$ for 5 minutes. Annealing was done in an ambient environment to allow the films to oxidize. The atomic percentage of oxygen on the surface of these films is measured using Energy Dispersive X-Ray Analysis (EDAX). The EDAX results displaying the oxidation trends in sputtered and MOVPEgrown AlN thin films are shown in Figure 1. 


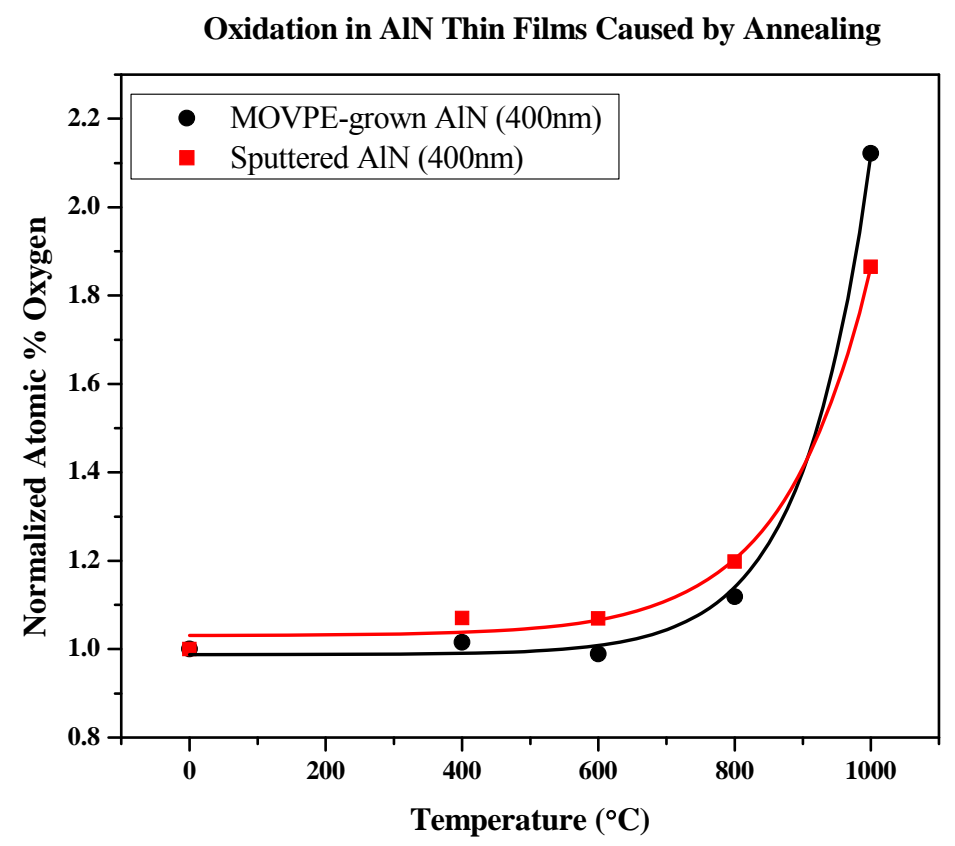

Figure 1 - Oxidation trends in sputtered and MOVPE-grown AlN

Solid circular platinum contacts were deposited on the top of the AlN films after annealing using a standard photolithography technique and an aluminum backside contact was sputtered onto the back of each wafer. An AC signal was used to actuate the films and a PSV400 Scanning Head Laser Doppler Vibrometer (LDV) was employed to measure the picometer level displacement of the AIN films in order to determine how the piezoelectric properties of thin AlN films respond after exposure to high temperatures. The results of are shown in Table 2.

Table 2

\begin{tabular}{|l|l|}
\hline Sample & $\mathbf{d}_{\mathbf{3 3}}(\mathbf{p m} / \mathbf{V})$ \\
\hline Sputtered Unannealed & 3.31 \\
\hline Sputtered Annealed $\left(1000^{\circ} \mathrm{C}\right)$ & 1.03 \\
\hline MOVPE-grown Unannealed & 15.38 \\
\hline MOVPE-grown Annealed $\left(1000^{\circ} \mathrm{C}\right)$ & 4.08 \\
\hline
\end{tabular}

A high temperature furnace was built that is capable of measuring the $\mathrm{d}_{33}$ of sputtered and MOVPE-grown AIN films while annealing the films in a high temperature environment. The furnace consists of a stainless steel chamber with a 1 inch diameter $\mathrm{Al}_{2} \mathrm{O}_{3}$ button heater that is rated up to $1200^{\circ} \mathrm{C}$ and connected to a DC power supply. An electrical feed-through on the side of the chamber allows for electrically probing the sample while the chamber is taken to high temperatures and a gas feed-through allows for the flow of various gasses during high temperature testing. The gas flow rate can be increased up to $20 \mathrm{scfh}$ (approximately 9500 $\mathrm{sccm}$ ). The top of the furnace has a 1 inch thick 1 inch diameter sapphire window located directly above the button heater. The LDV is mounted over the top of the furnace so that the laser travels through the window and onto the sample which is resting on top of the heater. 
Prior to high temperature testing, sputtered AIN samples are annealed in the RTA in a nitrogen environment at $600^{\circ} \mathrm{C}$ for 1 hour. Annealing the samples prior to in-situ tests assures that no annealing effects of the crystal will be encountered during testing. This preparation is done in a $\mathrm{N}_{2}$ environment so the films will not oxidize causing a lower $\mathrm{d}_{33}$ at the beginning of the measurements. MOVPE-grown films are grown at a much higher temperature than the in-situ temperature will reach, so the pre-test annealing preparation is unnecessary for these films.

A bondpad was fabricated for the AlN samples because the $400 \mu \mathrm{m}$ platinum contacts cannot be probed directly from the electrical feed-through. Large Pt contacts were deposited onto a $\mathrm{Si} / \mathrm{SiO}_{2}$ wafer using a standard photolithography technique and a thin layer of titanium was used as an adhesion layer. The backside of the AlN test sample was bonded to one of the Pt contacts on the bondpad using a temperature resistant silver paste then the paste was cured in room temperature for 2 hours followed by a 2 hour $90^{\circ} \mathrm{C}$ curing bake. Gold wire-bonding was used to probe the $400 \mu \mathrm{m}$ Pt contacts on the test sample from another Ti/Pt contact on the bondpad. By probing the contacts on the bondpad from the electrical feed-through, the signal is relayed to the

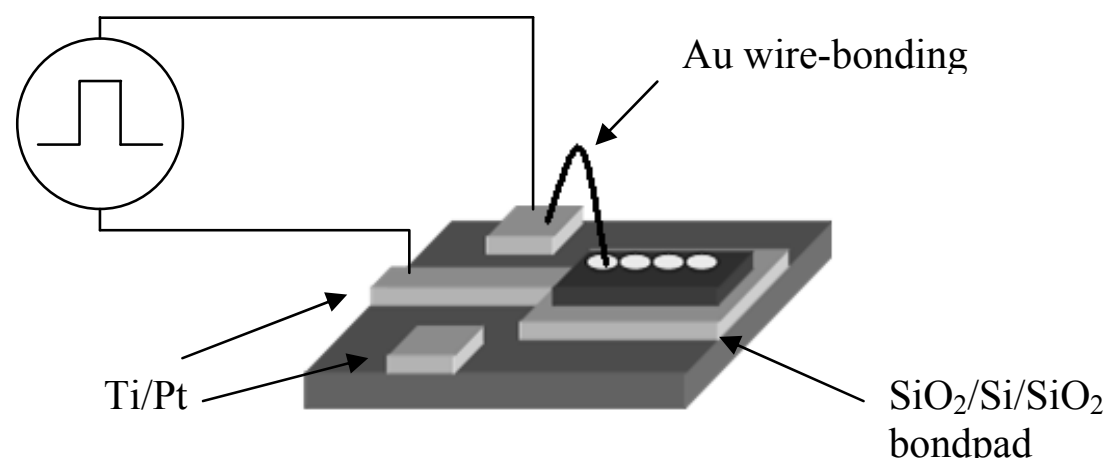

Figure 2 - AlN sample on bondpad with gold wire-bonding used to probe top contacts top and backside of the sample for actuation.

The furnace is heated by increasing the power to the button heater inside the furnace. During testing, the temperature of the furnace was increased at a rate of $10^{\circ} \mathrm{C} /$ minute while $\mathrm{N}_{2}$ gas was flowing through the chamber at a rate of $2 \mathrm{scfh}$ (approximately $950 \mathrm{sccm}$ ). The temperature inside the furnace was held to within $\pm 5^{\circ} \mathrm{C}$ of the target temperature while $\mathrm{d}_{33}$ measurements were taken. A $3.5 \mathrm{KHz}$ AC signal was supplied to the electrical feed-through at varying peak-peak voltages up to $20 \mathrm{~V}$ while the picometer level displacement was measured by the LDV. The $\mathrm{d}_{33}$ of sputtered and MOVPE-grown films were measured at temperatures up to $300^{\circ} \mathrm{C}$. The results of these measurements are summarized in Figure 3. 


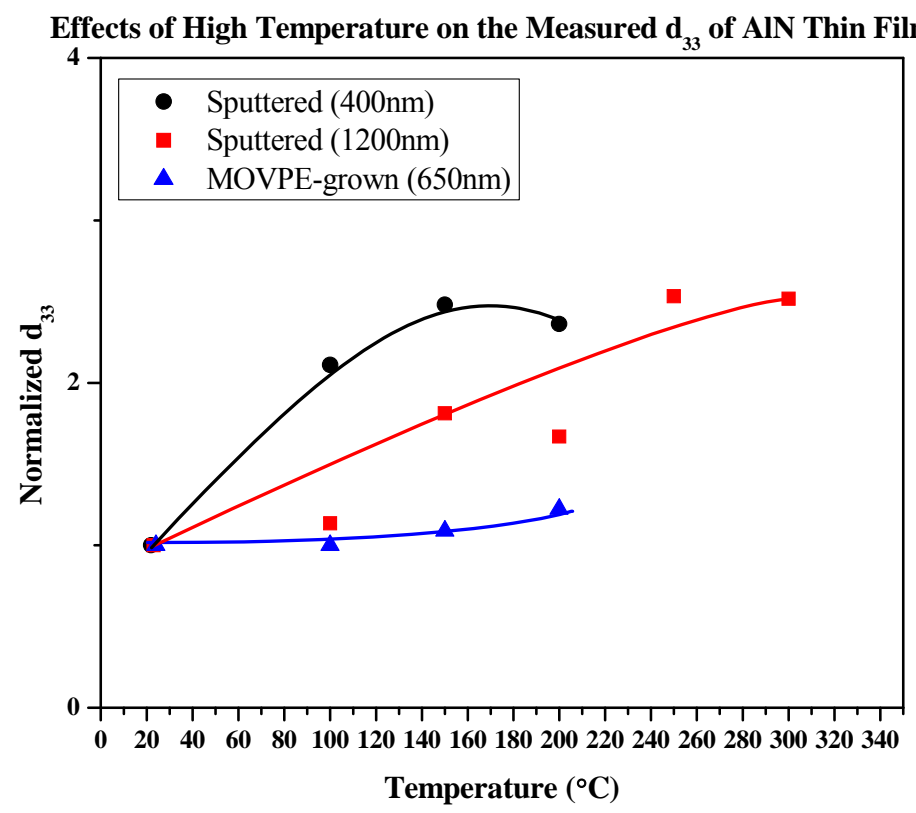

Figure 3 - In-situ measurements of the piezoelectric response of sputtered and MOVPE-grown AIN thin films

\section{DISCUSSION}

The results in Figure 1 show that sputtered films oxidize more than MOVPE-grown films at lower temperatures probably due to the different crystalline quality achieved by the two methods of deposition. At temperatures close to $1000^{\circ} \mathrm{C}$ both films oxidize rapidly as expected and the $d_{33}$ of annealed samples is lower compared to room temperature measurements of unannealed samples (Table 2). After annealing at $1000^{\circ} \mathrm{C}$, the measured $\mathrm{d}_{33}$ of both films reduced to about $25 \%$ of the original response of the unannealed films. There is a correlation between the oxidation results in Figure 1 and the $\mathrm{d}_{33}$ results in Table 2 leading to the conclusion that surface oxidation in AIN films drastically reduces piezoelectric response.

In-situ $\mathrm{d}_{33}$ measurements have been taken up to $300^{\circ} \mathrm{C}$. In Figure 3, it is evident that there is an increase in the measured $\mathrm{d}_{33}$ as the annealing temperature increased. AlN is a pyroelectric material so this increase could be attributed to a charge density increase due to high temperature [3]. However, this effect can be disregarded because it is likely that the power supply used to actuate the films will sink any extra charge produced in the films. The increase in the measured $\mathrm{d}_{33}$ could be caused by the difference in thermal expansion coefficients between AlN and Si. At $100^{\circ} \mathrm{C}$, the thermal expansion coefficients of $\mathrm{Si}$ and a-plane AlN are roughly $3.1 \times 10^{-6} / \mathrm{K}$ and $4.2 \times 10^{-6} / \mathrm{K}$, respectively [4,5]. At high temperatures, the AlN film expands more than the Si substrate, decreasing the lattice mismatch allowing the AlN to behave more like an unclamped film. However, a more detailed study of clamped and unclamped AlN films, including in-situ measurements of the $\mathrm{d}_{33}$, will need to be conducted to verify these trends.

At temperatures higher than $300^{\circ} \mathrm{C}$, the thin sputtered AlN films become conductive and when the temperature is decreased to $23^{\circ} \mathrm{C}$, these previously insulating films still conduct. This was not seen in films that had been annealed in the RTA prior to $d_{33}$ measurements. To find the relation between oxidation and $\mathrm{d}_{33}$, AlN films were annealed at $1000^{\circ} \mathrm{C}$ prior to measurements 
and AlN films used for in-situ tests were pre-annealed $600^{\circ} \mathrm{C}$. These films were not conducting when room temperature measurements were taken, so applying an electric field across the sample at high temperatures appears to damage the films. MOVPE-grown films became conductive at $400^{\circ} \mathrm{C}$ leading to the conclusion that a film with a poor crystalline quality may be more susceptible to damage from applying a voltage at those temperatures.

\section{CONCLUSIONS}

AlN is a robust material that remains piezoelectric above $1000^{\circ} \mathrm{C}$ but if the film is annealed in a harsh environment, oxidation could reduce the piezoelectric response. This paper has shown that AlN films oxidize drastically when annealed in an ambient environment causing a large reduction in the $d_{33}$ of the material. If the films are protected from oxidation, the $d_{33}$ of the material may be preserved up to $1000^{\circ} \mathrm{C}$ in any environment. Methods used to protect the films from oxidation while retaining the original piezoelectric response are currently under investigation.

In-situ $\mathrm{d}_{33}$ measurements of AlN films have been taken at temperatures up to $300^{\circ} \mathrm{C}$. The $\mathrm{d}_{33}$ appears to increase as temperature increases. This trend is likely caused by stress at the AlN/Si interface increasing with high temperatures. The films become conductive at temperatures above $300^{\circ} \mathrm{C}$ which compromises $\mathrm{d}_{33}$ measurements. It is important to understand why the films conduct at this temperature in order to proceed with in-situ measurements.

\section{ACKNOWLEDGMENTS}

This technical effort was performed in support of the National Energy Technology Laboratory's on-going research in high temperature flow control hardware for advanced power systems under the RDS contract DE-AC26-04NT41817. This work was also supported in part by, AIXTRON and NSF RII contract EPS 0554328 for which WV EPSCoR and WVU Research Corp matched funds.

\section{REFERENCES}

1. J.W. Lee, I. Radu, M. Alexe, J. Materials Science, 13, 131-137, 2002.

2. Kazuhiko Kano, Kazuki Arakawa, Yukihiro Takeuchi, Morito Akiyama, Naohiro Ueno, Nobuaki Kawahara, Sensors and Actuators, A, 130-131, 397-402, 2006

3. V. Fuflyigin, E. Salley, A. Osinsky, P. Norris, App. Phys. Letters, V. 77, 19, 2000

4. Yasumasa Okada, Yozo Tokumaru, J. Appl. Phys. 56 (2), 1984

5. W.M. Yim, R.J. Paff, J. Appl. Phys. 45(3), 1974 